Revista Destaques Acadêmicos, Lajeado, v. 12, n. 3, 2020. ISSN 2176-3070

DOI: http://dx.doi.org/10.22410/issn.2176-3070.v12i3a2020.2607

http://www.univates.br/revistas

\title{
NÍVEL DE ATIVIDADE FÍSICA E QUALIDADE DE VIDA DE PROFISSIONAIS E ESTAGIÁRIOS DE EDUCAÇÃO FÍSICA DE ACADEMIAS DE LAJEADO/RS
}

\author{
Daiana Schmitz ${ }^{1}$, Rodrigo Lara Rother ${ }^{2}$
}

Resumo: Este estudo teve como objetivo identificar os níveis de atividade física (AF) e qualidade de vida (QV) de profissionais e estagiários de Educação Física que trabalham nas academias de musculação da cidade de Lajeado/RS. Quanto à metodologia utilizada, o estudo caracteriza-se como uma pesquisa quantitativa, exploratória, transversal e correlacional, sendo composta por 44 sujeitos (26 profissionais e 18 estagiários de Educação Física - Bacharelado), todos atuantes em academias de musculação do município, que possuem carga horária mínima de 20h semanais. Para determinar os níveis de AF foi utilizado o Questionário Internacional de Atividade Física (IPAQ versão curta) e para determinar a QV foi utilizado o questionário WHOQOL-Bref. Os resultados encontrados para os níveis de AF foram de 15,91\% classificados como baixos, 20,45\% como moderados e 63,64\% como vigorosos. Todos os domínios da QV apresentaram valores satisfatórios, sendo o domínio Físico como o de maior escore (78,57\%), enquanto o domínio Ambiente o menor (68,18\%), ambos classificados como "Bom". Dados do presente estudo permitem concluir que profissionais que atuam em academias de musculação do município de Lajeado apresentam, em sua maioria, um nível de AF vigorosa e apresentam resultados bons em relação a QV. Não houve correlação estatisticamente significativa entre a intensidade da AF e a QV.

Palavras-chave: Atividade profissional; Sedentarismo; Saúde; Qualidade de Vida.

\section{INTRODUÇÃO}

Nas últimas décadas, estão havendo mudanças nos hábitos de vida da população brasileira. O país enfrenta dificuldades com o aumento de peso da população e, frequente, o crescimento do sedentarismo. Consequentemente, cresce o número de doenças, principalmente as de ordem cardiovascular.

1 Graduada do Curso de Educação Física Bacharelado da Universidade do Vale do Taquari UNIVATES, Lajeado/RS. E-mail: daiana.schmitz@universo.univates.br

2 Doutor, professor do Curso de Educação Física da Universidade do Vale do Taquari UNIVATES, Lajeado/RS. E-mail: rodrigorother@univates.br 
Segundo Brito e Duarte (2012) e Raddi (2014), há um aumento do sedentarismo no Brasil em regiões e públicos diferentes. O sedentarismo está se tornando uma epidemia mundial, sendo que um dos fatores que contribui para isso é a invasão tecnológica, levando à prevalência de excesso de peso e obesidade na população (MATSUDO et al., 2007). A modernização dos processos produtivos é um dos responsáveis pelo crescimento de sujeitos com obesidade e sobrepeso, pois os brasileiros gastam cada vez menos energia no seu dia a dia. São provindas, também, das mudanças nos hábitos alimentares e da falta de atividade física (AF), influenciados pela disponibilidade de alimentos com alto valor energético e pelo aumento do sedentarismo (CARLUCCI et al., 2013). Carneiro et al. (2003) afirmam que o sedentarismo se encontra associado a doenças e diversas condições metabólicas, como obesidade, hipertensão, diabetes, alteração do perfil lipídico e câncer.

Sabe-se que a AF é um componente importante na vida diária dos indivíduos por promover benefícios psíquicos, físicos e cognitivos à saúde, independentemente da idade e gênero, podendo ser praticada em forma de desporto ou lazer. Segundo a Organização Mundial da Saúde (OMS) (2014), a AF é qualquer movimento corporal produzido pelos músculos esqueléticos, resultando em consumo de energia, incluindo atividades no trabalho, jogos, viagens, tarefas domésticas e lazer.

Segundo Nahas (2006) apud Castro (2009), a AF contribui com o aumento da massa muscular, redução da massa adiposa, melhoria nas funções cardiorrespiratórias, redução dos eventos de doenças coronarianas, prevenção de doenças adquiridas, alívio do stress e depressão, aumento da flexibilidade e melhora da saúde mental e cognitiva.

São inúmeros os benefícios que o exercício físico proporciona para a saúde da população. Além de auxiliarem na estética, como diminuição do tecido adiposo, proporcionam uma melhora na prevenção, redução e/ou manutenção de doenças crônicas. Pedersen e Saltin (2015) investigaram vinte e seis doenças diferentes, como doenças psiquiátricas, neurológicas, metabólicas, cardiovasculares, pulmonares, distúrbios músculo esqueléticos e câncer, a fim de fornecer informações atualizadas baseadas em evidências sobre os tipos de exercícios, recomendações e contraindicações para cada uma das vinte e seis enfermidades, mostrando mais uma vez a importância da prática.

Os benefícios da AF são bastante conhecidos, e ainda há uma grande parcela da população levando um estilo de vida relativamente sedentário. Estudo realizado em São Paulo com profissionais da rede pública estadual de ensino, buscou avaliar os níveis de AF de 1681 docentes, dos quais apresentaram $46,3 \%$ níveis baixos, $42,7 \%$ níveis moderados e $11 \%$ níveis altos de AF. Concluiu-se que a maioria estes profissionais classificam-se como sedentários. Os autores chamam a atenção nas construções de políticas públicas em regiões específicas das cidades e que requerem maior atenção, centradas em atender esta população sedentária para adesão à prática de AF (BRITO et al., 2012). 
Sabe-se que um dos motivos pelos quais os profissionais da saúde não praticam exercício físico é pela rotina movimentada, desconforto, preguiça, restrição médica, tempo para os filhos e esposa e de uma jornada de trabalho longa (DUARTE et al., 2012). Contudo, é possível arranjar um tempo para a prática, o que falta, é decidir se desejam aderir a prática ou não, ainda, o profissional se dedicar a uma hora destinada a ele. Como se não bastassem as desculpas, os Profissionais de Educação Física e Personal Trainer acabam assumindo elevadas cargas horárias de trabalho uma vez que receberem por hora, deixando-os exaustos para treinar. Estas horas sequenciais trabalhadas também impedem de conseguir parar para realizar uma refeição, prejudicando na qualidade alimentar do mesmo. Em um estudo realizado por Espirito-Santo e Mourão (2006) mostram que a média de horas semanais trabalhadas por 15 profissionais de academias de musculação no RJ é de 50,7h, sendo esta bem acima das 40h semanais previstas nas leis trabalhistas, segundo Artigo 58 do Decreto-Lei 5.452/43 (CLT).

Estes profissionais podem atuar em diferentes ambientes, dentre eles academias, estúdios pequenos especializados, residências, parques ou praças, clubes e outros. Periodizam programas de treinamento físico individualizado com o objetivo de desenvolver condicionamento físico, hipertrofia, redução massa adiposa, entre outros. Segundo o Artigo 01 do Conselho Federal de Educação Física $n^{\circ}$ 046/2002, o Profissional de Educação Física é especialista em atividades físicas, podendo ministrar aulas ginásticas, como jump, spinning, lutas, capoeira, artes marciais, danças, atividades rítmicas, expressivas e acrobáticas, musculação, lazer, recreação, reabilitação, ioga, ginástica laboral e etc. Sua competência é prestar serviços que favoreçam o desenvolvimento da educação corporal e da prevenção, promoção, proteção, manutenção e reabilitação na saúde, auxiliando nos ganhos adequados de desempenho e condicionamento físico, contribuindo na melhora da qualidade de vida $(\mathrm{QV})$.

Atualmente, a maioria das academias de musculação possuem aulas de ginástica, e junto a necessidade de possuir profissionais capacitados para atender a demanda necessária. $\mathrm{O}$ professor na tentativa de melhorar suas perspectivas de atendimento necessita estudar, especializar-se, treinar e utilizar variadas metodologias de prescrição de exercícios, variando os movimentos e coreografias com o objetivo de atraírem cada vez mais as pessoas para a prática de exercícios físicos (CASTRO, 2009).

De acordo com Nunes e Freire (2006), diversos são os estudos que associam os fatores de desgaste físico e estresse entre profissionais de saúde, gerados por situações no trabalho. Sabendo da rotina diária de trabalho e possíveis complicações relacionadas, estes dados demonstram o quanto é necessário investigar se este público apresenta uma boa QV, uma vez que a atuação destes profissionais em academias de musculação demanda permanecer em ortostase por longos períodos e um esforço físico que necessita deslocar-se, manusear pesos para os alunos e permanecerem, muitas vezes, em 
má postura para auxiliar os alunos na execução de determinados exercícios (ESPÍRITO-SANTO; MOURÃO, 2006).

Folle e Farias (2012) realizaram uma pesquisa em Palhoça/SC com o objetivo de avaliar a QV e a AF de 71 profissionais escolares, sendo que $52,1 \%$ foram considerados inativos, $29,6 \%$ moderadamente ativos e $18,3 \%$ fisicamente ativos. Os entrevistados justificaram a falta da prática por apresentarem dores físicas, estresse, problemas de coluna, depressão, patologias, estas geradas devido ao seu ambiente de trabalho.

A QV é um termo que vem sendo bastante discutido atualmente, sendo concebido pela OMS (2014) como a percepção que a população enxerga sobre sua posição na vida, no contexto da cultura, dos sistemas de valores nos quais vivem e em relação a seus objetivos, expectativas, padrões e preocupações.

Quando se fala em $\mathrm{QV}$, principalmente para profissionais da área da saúde, logo surge a ideia de que a prática de atividades físicas e esportivas traz influências benéficas na QV. Segundo Macedo et al. (2003), a AF está relacionada a uma melhor QV. Em seu estudo, os autores compararam a QV de 33 universitários praticantes de musculação com a de 36 universitários sedentários. Foram encontradas diferenças significativas entre os grupos, da qual os resultados apresentaram em todos os aspectos uma melhor QV por parte dos praticantes de musculação.

A QV relaciona-se com o bem estar físico, social e emocional, sendo que um dos meios para o seu desenvolvimento é o exercício físico, quando prescritos corretamente (MACEDO et al., 2003). Uma vida com nível de AF mais ativa melhora significativamente a $\mathrm{QV}$ das pessoas, trazendo satisfação e bem estar para os indivíduos (SILVA; NAHAS, 2004). Mas, será que ter uma rotina de exercícios físicos ativos para os profissionais de academias de musculação significa por si só ter uma boa QV? Atualmente, os hábitos de vida e as demandas exigidas no trabalho estão levando os trabalhadores a desenvolverem distúrbios associados às atribuições diárias, má alimentação, poucas oportunidades de lazer, pouco tempo para o descanso e sono, contribuindo desta forma para a má QV (MELEIRO, 2002 apud SANTOS et al., 2013).

Sabendo que os profissionais de educação física trabalham com conceitos de QV e AF e acreditando que estes profissionais deveriam apresentar um estilo de vida ativo e saudável, o presente trabalho teve por objetivo identificar e correlacionar os níveis de AF e QV de profissionais de academias de musculação da cidade de Lajeado, Rio Grande do Sul, por meio do Questionário Internacional de Atividade Física (IPAQ) versão curta e Questionário WHOQOL-Bref. 


\section{PROCEDIMENTOS METODOLÓGICOS}

A presente pesquisa utilizou-se de uma abordagem quantitativa, correlacional e comparativa, da qual participaram 44 sujeitos, sendo 26 profissionais e 18 estagiários, que fazem parte do quadro de funcionários de sete academias do município de Lajeado/RS. Os participantes são formados e acadêmicos do curso de Educação Física - Bacharelado e exercem a função de Personal Trainer, monitores de musculação e/ou profissionais de Ginástica de Academia. Para inclusão na amostra foi considerada carga horária mínima de trabalho de 20 horas semanais.

Para classificar os resultados de forma mais harmoniosa, optou-se por dividir os participantes em dois grupos, sendo Grupo 1 (G1) os que trabalham somente como instrutores na musculação e/ ou Personal Trainer e Grupo 2 (G2) composto pelos que trabalham como instrutores de musculação e/ou personal trainer e também ministram aulas de ginástica. Essa escolha foi feita pelo fato de que profissionais que trabalham com ginástica necessitam atuar fisicamente na realização das suas atividades profissionais.

Os participantes responderam três questionários, os quais foram entregues nas academias onde trabalham para que levassem para casa, respondessem e devolvessem em data agendada com os pesquisadores. Estes questionários foram: 1-Perfil Profissional; 2-IPAQ versão curta; e 3-WHOQOLbref;

O questionário Perfil Profissional foi composto por questões sobre a idade, sexo, formação, horas trabalhadas entre outras para compreender o perfil dos participantes. Para medida do nível de AF foi utilizado o Questionário Internacional de Atividade Física - IPAQ versão curta, contendo perguntas em relação às atividades que realiza no trabalho, deslocar-se para algum lugar, lazer, exercício, como parte das suas atividades em casa ou no jardim, tempo de caminhada e tempo sentado. As questões foram estruturadas para fornecer contagens separadas sobre atividades de intensidade vigorosa, moderada, caminhadas e tempo sentado, sendo que estas foram respondidas com referência à última semana. Já para identificar a QV foi utilizado o questionário WHOQOL-bref, um instrumento que avalia as últimas duas semanas do entrevistado. Este questionário é composto por 26 questões nas quais o sujeito pode apresentar sua resposta por meio de escores que variam de um a cinco, sendo a condição pior no escore um e a melhor cinco. As questões são divididas em domínios físico, psicológico, relações sociais e meio ambiente.

Para tratamento dos resultados foi utilizada a análise descritiva com valores de média e desvio padrão, registrados e tabulados no Microsoft Excel 2010. Os resultados de ambas análises foram correlacionados através da Correlação de Person e para comparação entre grupos foi utilizado o Teste $T$ Student para amostras pareadas, adotando como grau de significância $p<0,05$. 
Além disso, os resultados do IPAQ foram classificados em Vigoroso, Moderado e Baixo e do WHOQOL em Muito Ruim, Ruim, Nem Ruim Nem Boa, Boa e Muito Boa, conforme sugerido por Padrão (2008).

Esta pesquisa cumpriu com todos os requisitos éticos necessários e foi aprovada pelo Comitê de Ética da Universidade do Vale do Taquari UNIVATES, sob parecer número 2.887.616.

\section{RESULTADOS}

Como Perfil Profissional dos participantes do estudo foi identificado que, dos 44 entrevistados, $41 \%(n=18)$ são do sexo feminino e $59 \% \quad(n=26)$ masculino, trabalham uma carga horária mínima de $20 \mathrm{~h}$ e máxima de $67 \mathrm{~h}$ semanais. Na Tabela 1 pode-se identificar o perfil, apresentando médias dos resultados obtidos nesse aspecto.

Tabela 1- Perfil dos profissionais de Educação Física participantes.

\begin{tabular}{c|c|c|c|c|c|c}
\hline & $\begin{array}{c}\text { IDADE } \\
\text { MÉDIA }\end{array}$ & $\begin{array}{c}\text { HORAS } \\
\text { TRAB. } \\
\text { MÉDIA }\end{array}$ & $\begin{array}{c}\text { ESTUDANTES } \\
\mathbf{n = 1 8}\end{array}$ & $\begin{array}{c}\text { FORMADOS } \\
\mathbf{n = 2 6}\end{array}$ & $\begin{array}{c}\text { MULHERES } \\
\mathbf{n = 1 8}\end{array}$ & $\begin{array}{c}\text { HOMENS } \\
\mathbf{n = 2 6}\end{array}$ \\
\hline G 1 & $32,75 \pm 5,13$ & $35,63 \pm 11,27$ & $28 \%$ & $72 \%$ & $31 \%$ & $69 \%$ \\
G 2 & $27,08 \pm 4,94$ & $31,33 \pm 5,11$ & $75 \%$ & $25 \%$ & $67 \%$ & $33 \%$ \\
GERAL & $31,20 \pm 5,69$ & $34,45 \pm 9,92$ & $41 \%$ & $59 \%$ & $41 \%$ & $59 \%$ \\
\hline
\end{tabular}

Fonte: Autores do estudo (2020).

No G1 foram 10 entrevistados do sexo feminino e 22 do sexo masculino, com idade mínima de 23 e máxima de 54 anos, trabalham no mínimo 20h e no máximo $67 \mathrm{~h}$ semanais, sendo 23 formados em Educação Física e nove acadêmicos do curso. Já no G2, foram oito do sexo feminino e quatro, masculino, com idade mínima de 20 e máxima de 43 anos, atuando no mínimo 20h e no máximo $48 \mathrm{~h}$ semanais, sendo três formados e nove acadêmicos. Quando comparados os perfis dos grupos, houve diferença estatisticamente significativa na idade a favor do G1 ( $\mathrm{p}=0.012$ ), haja visto que $72 \%$ destes é formado e tiveram mais tempo para concluir seus estudos. Já nas horas semanais trabalhadas, a diferença não se conformou ( $\mathrm{p}=0,1029)$.

Quanto aos níveis de AF, a Tabela 2 mostra que a maioria dos profissionais participantes do estudo estão fisicamente ativos e classificados como praticantes de "Atividade Vigorosa" (63,64\%). 
Tabela 2 - Níveis de Atividade Física (IPAQ)

\begin{tabular}{c|c|c|c|c}
\hline & Nível de AF & Nível de AF & Nível de AF & Nível de AF \\
\hline & METS/min/sem & BAIXO & MODERADO & VIGOROSO \\
\hline G1 & $2708,85 \pm 994,82$ & $15,63 \%$ & $15,63 \%$ & $68,75 \%$ \\
G2 & $2790,5 \pm 1814,83$ & $16,67 \%$ & $33,33 \%$ & $50,00 \%$ \\
GERAL & $2731,12 \pm 1212,44$ & $15,91 \%$ & $20,45 \%$ & $63,64 \%$ \\
\hline
\end{tabular}

Fonte: Autores do estudo (2020).

A QV geral (Tabela 3), tanto quando se analisa a média quanto os quatro domínios de forma isolada, apresentam valores classificados como "Boa" (72,72 pontos). Quando observados os grupos separadamente, destaques para os valores de QV Físico do G1, classificado no limite superior como "Muito Bom" (80,92 pontos) e para QV Psicológico do G2, classificada no limite inferior como "Nem ruim nem boa" (61,46 pontos).

Tabela 3 - Qualidade de Vida (WHOQOL-Bref) dos profissionais de Educação Física.

\begin{tabular}{c|c|c|c|c|c}
\hline & Níveis de QV & Níveis de QV & Níveis de QV & Níveis de QV & Níveis de QV \\
\hline & QV Físico & QV Psicológico & QV Social & QV Ambiental & QV Geral \\
\hline G1 & 80,92 & 74,09 & 74,72 & 69,24 & 74,74 \\
G2 & 72,32 & 61,46 & 70,14 & 65,37 & 67,32 \\
GERAL & 78,57 & 70,64 & 73,47 & 68,18 & 72,72 \\
\hline
\end{tabular}

Fonte: Autores do estudo (2020).

Quando comparados G1 e G2 quanto aos valores apresentados para $\mathrm{METS} / \mathrm{min} / \mathrm{sem}, \mathrm{AF}$, QV geral e QV nos quatro domínios, os resultados foram muito similares e não apresentaram diferenças estatisticamente significativas. Nesse aspecto, somente houve diferenças entre os grupos quando comparados QV geral ( $p=0,0003)$ e QV psicológica $(p=0,004)$, ambos a favor do G1.

Já quando realizada a correlação entre as variáveis Nível de AF e QV foi encontrada correlação positiva baixa $(\mathrm{r}=0,27)$, já entre METS $/ \mathrm{min} / \mathrm{sem}$ e QV foi encontrada correlação negativa ínfima $(\mathrm{r}=-0,03)$ e entre horas trabalhadas e QV geral correlação positiva ínfima $(r=0,08)$.

\section{DISCUSSÃO}

Este estudo apresenta dados do ano de 2018 sobre 44 profissionais e acadêmicos de Educação Física do município de Lajeado/RS, referente aos 
níveis de $\mathrm{AF}$ e QV. Não foram encontrados estudos iguais no município, o que tornam estes dados de extrema relevância para o entendimento do perfil dos profissionais desta cidade. O estudo mais próximo deste foi de Da Silva et al (2019), que avaliaram o nível de AT e a QV de professores de Educação Física da rede escolar no mesmo município, onde ambas as variáveis foram consideradas "boas", resultados estes semelhantes ao público aqui investigado.

Entre os níveis de AF vigorosa e moderada, 84,09\% se encontram com níveis adequados de AF. Apesar da pequena porcentagem de profissionais e futuros profissionais não atingirem um nível adequado de $\mathrm{AF}$, deve-se atentar e instigar quais os motivos que estes não aderem a prática, pois além de proporcionar bem-estar, esta área é capaz de influenciar e inspirar seus alunos e novos clientes a promoção de saúde. Desta forma, isto se aplica ao próprio profissional, pois a promoção a saúde, bem-estar e QV deve ser recíproca, tanto para ele como para seus alunos (ROCHA et al. 2016). Estes achados corroboram com os resultados de Cieslak et al. (2007), nos quais identificaram que 85 acadêmicos do Curso de Educação Física apresentam em sua maioria níveis de AF "Vigorosa", sendo a categoria "Insuficiente ativa" menor. Como a amostra refere-se a profissionais e estudantes de Educação Física, que possuem conhecimentos sobre os benefícios da prática da $\mathrm{AF}$, os resultados podem ter sido influenciados por isso. E, também, pelo gosto da prática de atividade/ exercício físico, visto que muitos escolhem a profissão de Profissional de Educação Física Bacharelado por estes motivos (KRUG; KRUG, 2017; MENDES; AZEVEDO, 2014).

Ao verificar qual o público que apresenta tais resultados insatisfatórios, três são profissionais de educação física e quatro estudantes de educação física. Para estes profissionais, os resultados que apresentaram e os classificaram como "Inatividade Física", podem ser justificados pelo excesso da carga horária, sendo que os sujeitos 9, 12 e 22 do G1 possuem carga horária semanal de 50h, $30 \mathrm{~h}$ e $27 \mathrm{~h}$ respectivamente. Acabam na maioria das vezes, como são autônomos e trabalham por hora, atendendo mais alunos para suprir as despesas mensais, consequentemente, deixando-os exaustos para treinar. Também, por terem a média de 39 anos possam estar substituindo horas livres por estar com a família. Estas justificativas vão de encontro com Duarte et al. (2012) que relata em seu estudo os motivos pelos quais os profissionais da saúde não praticam exercício físico. Sendo eles a rotina movimentada, preguiça, restrição médica, tempo para os filhos e esposa e de uma jornada longa de trabalho. Já para os estudantes de Educação Física, a escolha de não praticar atividades físicas pode ser justificada por, além de trabalharem uma carga horária média de $25 \mathrm{~h}$ semanais, onde os sujeitos 24 e 25 do G1 trabalham 30h e 20h semanais e sujeitos 2 e 12 do G2, trabalham $30 \mathrm{~h}$ e $20 \mathrm{~h}$ acumulando horas estudando para provas e realizando trabalhos para faculdade.

Quando analisadas as comparações entre os dois grupos, percebeuse que dois indivíduos do G2 se apresentaram "Insuficiente Ativos". Em sua 
maioria, os profissionais que ministram aulas de ginástica deveriam participar ativamente das aulas, não apresentando tais resultados. O acadêmico, na maioria das vezes, não consegue através da fala e rápida demonstração do exercício fazer com que os alunos executem da maneira correta. Deve-se considerar que o processo ensino/aprendizagem dos exercícios, em sua maioria, necessitam de demonstração por parte do professor (SILVA; NUNES, 2007).

De modo geral, a maior parte do grupo avaliou sua QV como "Boa" e "Muito Boa" na primeira questão do WHOQOL-bref (Como você avalia sua QV?), da mesma forma que ocorreu nos achados de Simões et al. (2011) nos quais $90,9 \%$ dos entrevistados, sendo 33 professores de Educação Física de Musculação e 44 alunos de Musculação, responderam ser "Boa" e "Muito Boa" sua QV. Os resultados aqui encontrados para QV, tanto Geral quanto nos quatro domínios, são semelhantes aos de Moreira (2009), Neto (2012), Rocha (2016), Cieslak (2007) e Silva et al. (2010). Ambos os grupos obtiveram escores entre 61-80, tendo como classificação geral da QV como "Boa", conforme classificação de Padrão (2008).

Para o G1, o Domínio Físico $(n=80,92)$ foi de maior pontuação, enquanto que o Domínio Ambiente $(n=69,24)$ menor, corroborando com os resultados encontrados no estudo de Cieslak (2007), o qual investigou 85 estudantes do Curso de Educação Física, 46 do sexo masculino e 35 feminino, com valores no Domínio Físico (n=77,2 e 72,2) e para Domínio Ambiente (n=61,0 e 63,5). Também para Simões et al. (2011), que encontraram valores no Domínio Físico $(n=83,45)$ e Domínio Ambiente $(n=69,03)$ em 33 professores de musculação de MG. Quando investigada a questão com maior pontuação negativa no Domínio Ambiente, percebe-se que a Q9 “Quão saudável é seu ambiente físico?" aparece com grande destaque. Para o domínio ambiente, as respostas podem ser justificadas pelas condições de trabalho, pois a academia de musculação, onde atua, é caracterizada como um ambiente físico de barulhos (ruídos de aparelhos, esteiras e pesos, música alta e algumas vezes não de agrado a todos, poluição e atrativos) (SILVA; NUNES, 2009). De acordo com Pereira, Santos e Viola (2000), a atuação profissional em ambientes de barulho levam os profissionais a elevar a intensidade da voz devido à competição sonora e à necessidade de superar os ruídos presentes. Portanto, como a maior parte cotidiana destes profissionais é em seus locais de trabalho, isso pode influenciar negativamente em sua percepção de qualidade de vida com relação a este domínio. Através do embasamento teórico foi possível compreender a importância de criar um ambiente adequado para que os profissionais de Educação Física possam atuar de forma produtiva e sintam-se motivados, melhorando ainda mais sua QV.

Quando comparados os resultados de QV geral, o G2 apresentou menor escore em relação ao G1 $(67,32 \pm 5,39)$. Dos quatro domínios do WHOQOLbref, o melhor escore foi no domínio físico $(n=72,32)$, enquanto que o menor foi no domínio psicológico $(n=61,46)$. Diferente dos resultados de Santos et al. (2013), cujos sujeitos entrevistados foram 62 professores de ginástica da cidade 
de Olinda- PE, que identificaram a melhor QV no domínio social e menor no ambiente, igual ao esperado e diferente dos resultados encontrados no presente estudo. A hipótese para este grupo era que o domínio ambiente seria o mais prejudicial, devido aos mesmos motivos acima relatados. Quanto a percepção de QV psicológico, Q7 “O quanto você consegue se concentrar?", foi a questão de maior frequência negativa. $\mathrm{O}$ fato da dificuldade da má concentração pode ser especulado pela má qualidade do sono destes entrevistados. Segundo Milano, Palma e Assis (2007), a restrição de horas de sono, sendo ela duração média diária de 4,5 horas, acumulada ao longo da semana, pode provocar prejuízos ao desempenho, fadiga, confusão e aumento na probabilidade de ocorrência de acidentes de trabalho. Ao investigar a Q16 "Quão satisfeito você está com seu sono?", 42\% relataram estar insatisfeito e muito insatisfeito.

Muitos profissionais de ginástica acabam ministrando mais de uma aula por dia e/ou até mesmo todos os dias, além de ficarem em pé praticamente durante toda a aula, demonstrando os movimentos a serem realizados, levando ao esgotamento e cansaço. Segundo Hartwig (2012), a voz passou a ser um dos principais instrumentos diários de trabalho, exigindo rapidez nas informações e motivação, sendo ela tão importante quanto a exigência física relacionada com sua profissão. Em seu estudo, analisou a saúde vocal de professores de ginástica, no qual identificou que esta variável apresentou menor pontuação no questionário $\mathrm{QV}$, com muitas queixas sobre desconforto laríngeo e rouquidão.

Por outro lado, o domínio psicológico para o G2 parece importante de ser discutido. Os transtornos psiquiátricos menores estão cada vez maiores entre trabalhadores (HARTWIG, 2012). Pensando nos profissionais de Educação Física, principalmente que os atuam com ginástica, a possível desvalorização profissional, questões financeiras, estrutura física do ambiente, pressões psicológicas pelo rendimento, acúmulo de atividades, necessidade de estar atendendo às expectativas do mercado de trabalho e ausência de resultados positivos percebidos no ambiente de trabalho e ingestão calórica inadequada podem contribuir para esse fato (NEVES, 1997 apud HARTWIG, 2012; ESPíRITO-SANTO; MOURÃO, 2006).

Muitos estudantes de Educação Física e Profissionais que ingressam em academias optam por ministrar aulas de ginástica devido à diferença em valores por aula que recebem entre atuar com Musculação e Ginástica. Mendes e Azevedo (2014) investigaram a remuneração de 52 Profissionais de Educação Física atuantes em academias de Brasília, sendo que o valor médio ( $R$ \$) da hora de ginástica era $20 \pm 4,2$, enquanto que da musculação, $10 \pm 3$, 2 . Contudo, atuar neste espaço necessita de grande controle emocional devido às exigências que a sociedade e mídia impõem.

Segundo Palma e Assis (2005), alguns profissionais fazem o uso de esteroides anabólicos androgênicos e aceleradores metabólicos a fim de alcançar um corpo necessário à atividade profissional, seja enquanto cartão de visita e comprovante de competência profissional, seja para aumentar o 
desempenho e reduzir o desgaste físico necessários a atuação em suas aulas. Para os mesmos autores, o corpo dos profissionais que atuam nas academias de ginástica funciona como uma espécie de "currículo", tido como exemplo ou modelo para seus alunos.

O preconceito que cerca os profissionais que estão fora desses "padrões de beleza e desempenho" pode estar influenciando diretamente na $\mathrm{QV}$, repercutindo de forma prejudicial sobre a saúde. Além desses aspectos, outro fator que necessita de controle emocional é por assumir uma posição de centralidade, onde todos os alunos centram a atenção no profissional, podendo julgar, positivamente, bem como negativamente, suas ações, posturas e aparência física. Sugere-se mais estudos sobre tal variável a fim de identificar os reais motivos que influenciam na diminuição da QV no domínio psicológico dos profissionais do G2, visto que a pontuação média no presente estudo foi de $61,46 \pm 7,29$, classificada como "Boa", pouco acima do limite classificado como "Nem ruim nem boa" (40-60).

Entre os professores de educação física que atuam em academias, Palma et al. (2007) verificaram que 54,4\% manifestaram dores frequentes em diferentes regiões do corpo. As queixas de dores foram, em sua maioria, referentes à região lombar $(36,2 \%)$ e aos membros inferiores $(20,1 \%)$. Muitos são os estudos que revelam locais frequentes de lesões articulares e musculares em profissionais, principalmente ministrantes de ginástica. Porém, mesmo diante destas afirmações, percebe-se que tanto o G1 como G2 apresentaram melhor pontuação no domínio físico. Apenas 1 sujeito do G2 necessita de tratamento médico e apresentou dificuldade em realizar o que precisa devido ao relato de dor. Talvez pela baixa quantidade de profissionais que atuam com ginástica entrevistados e não encontrar o público mais ativo em ginástica, não foram encontradas mais pontuações negativas no critério dor.

Ao correlacionar AF e QV geral, foi encontrado valor significativo baixo $(\mathrm{r}=0,27)$. Já para QV com METS/min/sem não houveram resultados significativos $(\mathrm{r}=0,003)$, ou seja, o maior gasto energético não melhora a $\mathrm{QV}$ geral. Segundo Silva e Nahas (2004), uma vida com nível de atividade física mais ativa melhora significativamente a qualidade de vida das pessoas, trazendo satisfação e bem-estar para os indivíduos. Porém, não foram encontrados resultados semelhantes no presente estudo. Estes achados vieram de encontro com as expectativas devido o conhecimento da rotina diária desse público. Ao correlacionar QV com horas trabalhadas não houve resultados significativos $(\mathrm{r}=0,008)$. Portanto, acreditando que quantidade de horas trabalhadas semanalmente e aumento da intensidade e frequência influenciassem na QV, esses aspectos não foram confirmados no presente estudo.

Quando comparados os resultados dos grupos em relação à QV em todos os domínios, somente houve diferença quando comparados QV geral $(\mathrm{p}=0,0003)$ e QV psicológica $(\mathrm{p}=0,004)$, ambos a favor do G1. Ressalta-se que artigos acadêmicos frisando o assunto por profissionais de Educação Física 
Bacharelado, atuantes em academias de musculação e ginástica, ainda são escassos.

\section{CONCLUSÃO}

Os dados obtidos permitem concluir que profissionais atuantes em academias de musculação do município de Lajeado, apresentam, em sua maioria, um nível de $\mathrm{AF}$ ativa de forma vigorosa e apresentam resultados satisfatórios em relação a QV. Não houve correlação estatisticamente significativa entre $\mathrm{METS} / \mathrm{min} / \mathrm{sem}$ e intensidade de AF com melhor QV. Maiores escores foram identificados na QV no domínio físico em ambos os grupos, enquanto que a QV no domínio ambiental foi menor no G1 e QV no domínio psicológico para o G2. Embora acreditando que quantidade de horas trabalhadas semanalmente e aumento da intensidade e frequência influenciassem na QV, esses aspectos não foram confirmados no presente estudo. Através do embasamento teórico foi possível compreender a importância de criar um ambiente adequado para que os profissionais de Educação Física possam atuar de forma produtiva e sintam-se motivados, melhorando ainda mais sua QV, evitando o abandono sua da profissão.

\section{REFERÊNCIAS}

ALMEIDA, M.A.B; GUTIERREZ, G.L; MARQUES, R. Qualidade de Vida: definição, conceitos e interfaces com outras áreas de pesquisa. São Paulo: Escola de Artes, Ciências e Humanidades - EACH/USP, 2012.

BRASIL. Lei n ${ }^{\circ}$ 5.452, de 1 de maio de 1943. Consolidação das Leis do Trabalho. Disponível em: <http://www.planalto.gov.br/ccivil_03/decreto-lei/Del5452.htm>. Acesso em: 06 mai. 2018.

BRITO, W. F. et al. Nível de atividade física em professores da rede estadual de ensino. Rev. Saúde Pública, v. 46, n. 2, p. 104-109, 2012.

CARLUCCI, E. M. S. et al. Obesidade e sedentarismo: fatores de risco para doença cardiovascular. Com. Ciências Saúde, v. 24, n. 4, p. 375-384, 2013

CARNEIRO, G. et al. Influência da distribuição da gordura corporal sobre a prevalência de hipertensão arterial e outros fatores de risco cardiovascular em indivíduos obesos. Rev. Assoc. Med. Bras., São Paulo, v. 49, n. 3, p. 306-3011, 2003.

CASTRO, S. C. O perfil do cliente do profissional de educação física que atua como personal trainer na região metropolitana de Belo Horizonte. 2009. $46 \mathrm{f}$. Trabalho de Conclusão de Curso - Curso de Educação Física Bacharelado, da Universidade Federal de Minas Gerais, Minas Gerais, 2009.

CONSELHO FEDERAL DE EDUCAÇÃO FÍSICA (CONFEF). Disponível em: < http://www.confef.org.br/confef/resolucoes/82>. Acesso em: 01 jun. 2018. 
CUNHA, R.A; MORALES, J.C.P; SAMULSKI, D.M. Análise da percepção de qualidade de vida de jogadores de voleibol: uma comparação entre gêneros. Revista Brasileira de Educação Física e Esporte, v.22, n. 4, p.301-2010, out./dez, 2008.

DUARTE, C. K. et al. Nível de atividade física e exercício físico em pacientes com diabetes mellitus. Rev. Assoc. Med. Bras., Brasília, v. 58, n. 2, p. 2015-221, 2012.

DA SILVA, J. S., DORNELLES, J. L., KOETZ L.C.E., DIAS, C.P., TIGGEMANN, C. L. Nível de Atividade Física e Qualidade de Vida dos professores de Educação Física da rede escolar de Lajeado/RS. Revista Brasileira De Ciências Da Saúde, 23(2): 2019.

ESPIRITO-SANTO, G.; MOURÃO,L. A auto -representação da saúde dos professores de educação física de academias. Rev. Bras. Cienc. Esporte, Campinas, v. 27, n. 3, p. 39-55, maio 2006.

FOLLE, A.; FARIAS, G. Nível de qualidade de vida e de atividade física de professores de escolas públicas estaduais da cidade de palhoça (SC). Revista Mackenzie de Educação Física e Esporte, Santa Catarina, v. 11, n. 1, p. 11-21, 2012.

FONTELLES, M.J. et al. Metodologia da pesquisa científica: diretrizes para a elaboração de um protocolo de pesquisa. Disponível em: <https:/ / cienciassaude. medicina.ufg.br/up/150/o/Anexo_C8_NONAME.pdf>. Acesso em: 19 maio 2018.

IPAQ (2005). Guidelines for Data Processing and Analysis of the Internacional Physical Activity Questionnaire. Disponível em: <http:/www.ipaq.ki.se/>. Acesso em: 12 maio 2016.

INTERDONATO, G.C, GREGUOL. M. Qualidade de Vida Percebida por Indivíduos Fisicamente Ativos e Sedentários. Rev. Bras. Ci. e Mov, v.18, n.1, p.61-67, 2010.

KRUG, Rodrigo de Rosso; KRUG, Hugo Norberto. Os motivos da escolha da profissão: licenciatura ou bacharelado em educação física. Revista Gestão Universitária, 2017. Disponível em <http:/ / gestaouniversitaria.com.br/artigos/osmotivos-da-escolha-da-profissao-licenciatura-ou-bacharelado-em-educacao-fisica $>$. Acesso em 10 nov. 2018.

MACEDO, C.S.G. et al. Benefício do exercício físico para a qualidade de vida. Revista Brasileira de Atividade Física \& Saúde, Pelotas, v 8, n. 2, p.19-27, 2003.

MATSUDO, S. M. Nível de atividade física da população do Estado de São Paulo: análise de acordo com o gênero, idade, nível socioeconômico, distribuição geográfica e de conhecimento. Rev. Bras. Ciên. e Mov., Brasília, v. 10, n. 4, p. 41-50, 2002.

MENDES, Alessandra Dias; AZEVÊDO, Paulo Henrique. O trabalho e a saúde do educador físico em academias: uma contradição no cerne da profissão. Rev Bras Educ Fís Esporte, São Paulo, 2014, Out-Dez; 28(4):599-615, 17p.

MILANO, F.M.; PALMA, A.; ASSIS, M. Saúde e trabalho dos professores de educação física que atuam com ciclismo indoor. EFDeportes- Revista Digital, n. 109, jun., 
2007;12. Disponível em: <http:/ / www.efdeportes.com/efd109/saude-e-trabalho-dosprofessores-de-educacao-fisica-que-atuam-com-ciclismo-indoor.htm>. Acesso em: 28 out 2018.

MOTA, J. et al. Atividade física e qualidade de vida associada à saúde em idosos participantes e não participantes em programas regulares de atividade física. Rev. Bras. Educ. Fís. Esp., São Paulo, v.20, n.3, p.219-25, jul./set. 2006

NUNES, M. F.; FREIRE, M. C. M. Qualidade de vida de cirurgiões-dentistas que atuam em um serviço público. Revista de Saúde Pública, São Paulo, v. 40, n. 6, p. 1019-1026, 2006.

OEHLSCHLAEGER, M. H. K. et al. Prevalência e fatores associados ao sedentarismo em adolescentes de área urbana. Rev. Saúde Pública, Pelotas, v. 38, n. 2, p. 157-163, 2004.

Organização Mundial da Saúde (OMS). Disponível em: <http:/ / www.who.int/ mediacentre/factsheets/fs385/en/>. Acesso em: 21 abril. 2018.

PALMA, A. et al. Trabalho e saúde: o caso dos professores de educação física que atuam em academias de ginástica. Cad. IPUB/UFRJ, v.13, p.11-30, 2007.

PEDERSEN, B. K; SALTIN, B. Exercise as medicine - evidence for prescribing exercise as therapy in 26 different chronic diseases. Scand J. Med. Sci. Sports, v. 3, n. 25, p. 1-72, 2015.

PETROSKI, E.C. Qualidade de vida no trabalho e suas relações com estresse, nível de atividade física e risco coronariano de professores universitários. 2005. 173 f. Tese - Programa de Pós-Graduação em Engenharia de Produção, da Universidade Federal de Santa Catarina, Santa Catarina, 2005.

RADDI, L. L. O. et al. Nível de atividade física e acúmulo de tempo sentado em estudantes de medicina. Rev. Bras. Med. Esporte, v. 20, n. 2, p. 101-104, mar./abr. 2014.

SANTOS, J.D.A. et al. Qualidade de Vida dos Professores de academia de ginástica da cidade de Olinda-Pernambuco. Rev. Educ. Física., v.24, n.2, p.225-231, 2013.

SILVA, D.K.; NAHAS, M.V. Atividade física habitual e qualidade de vida relacionada à saúde em mulheres com doença vascular periférica. Rev. Bras. Ci. e Mov. Brasília v. 1,2 n. 4, p. 63-68, dez. 2004.

SILVA, R. S. et al. Atividade física e qualidade de vida. Ciência e Saúde Coletiva, Pelotas, v. 15, n. 1, p. 115-120, 2010.

SIMÕES, K. L. et al. Prevalência de sedentarismo em professores de educação física: um estudo comparativo entre professores dos estados do Paraná e do Mato Grosso do Sul.

Revista Mackenzie de Educação Física e Esporte, Paraná, v. 11, n. 2, p. 151-160, 2012.

VILARTA, R; GUTIERREZ, G.L; MONTEIRO, M.I. Qualidade de vida: evolução dos conceitos e práticas no século XXI. Campinas: Ipes, 2010. 